Article

\title{
Non-Thermal Plasma Combined with Cordierite-Supported Mn and Fe Based Catalysts for the Decomposition of Diethylether
}

\section{Quang Hung Trinh and Young Sun Mok*}

Department of Chemical and Biological Engineering, Jeju National University, Jeju 690-756, Korea;

E-Mail: quanghung1020@gmail.com

* Author to whom correspondence should be addressed; E-Mail: smokie@jejunu.ac.kr;

Tel.: +82-64-754-3682; Fax: +82-64-755-3670.

Academic Editor: Jean-François Lamonier

Received: 3 February 2015 / Accepted: 22 April 2015 / Published: 29 April 2015

\begin{abstract}
The removal of dilute diethylether (DEE, concentration: $150 \mathrm{ppm}$ ) from an air stream (flow rate: $1.0 \mathrm{~L} \mathrm{~min}^{-1}$ ) using non-thermal plasma combined with different cordierite-supported catalysts, including $\mathrm{Mn}, \mathrm{Fe}$, and mixed Mn-Fe oxides, was investigated. The experimental results showed that the decomposition of DEE occurred in a one-stage reactor without the positive synergy of plasma and supported catalysts, by which $c a .96 \%$ of DEE was removed at a specific input energy (SIE) of $c a$. $600 \mathrm{~J} \mathrm{~L}^{-1}$, except when the mixed $\mathrm{Mn}-\mathrm{Fe} / \mathrm{cordierite}$ was used. Among the catalysts that were examined, Mn-Fe/cordierite, the catalyst that was the most efficient at decomposing ozone was found to negatively affect the decomposition of DEE in the one-stage reactor. However, when it was utilized as a catalyst in the post-plasma stage of a two-part hybrid reactor, in which $\mathrm{Mn} /$ cordierite was directly exposed to the plasma, the reactor performance in terms of DEE decomposition efficiency was improved by more than $10 \%$ at low values of SIE compared to the efficiency that was achieved without Mn-Fe/cordierite. The ozone that was formed during the plasma stage and its subsequent catalytic dissociation during the post-plasma stage to produce atomic oxygen therefore played important roles in the removal of DEE.
\end{abstract}

Keywords: DBD plasma; one-stage arrangement; diethylether; Mn-Fe mixed oxides; cordierite honeycomb 


\section{Introduction}

The use of non-thermal plasma (NTP) for the abatement of volatile organic compounds (VOC) has become increasingly attractive to many researchers in the field of air puification [1-6]. NTP offers a number of advantages over conventional methods for air pollution control, namely usability at ambient temperature and pressure, system compactness, and flexible power adjustment [7,8]. However, the use of NTP alone results in a poor selectivity towards the target compounds and low energy efficiency, which may present barriers to practical applications.

The combination of non-thermal plasma with catalysis is a feasible way to overcome the abovementioned issues as they complement each other. NTP is nonselective in chemical reactions, but it can be ignited under normal conditions. On the other hand, catalysis is featured as a selective process, but most catalysts are only activated at high temperatures. The most important characteristic of this complementary combination is that plasma enables catalysts to function at low temperatures, offering advantages for the treatment of VOCs in terms of energy efficiency, product selectivity and carbon balance $[9,10]$. In a plasma-catalysis system, a catalyst can either be included in the same reactor in a one-stage arrangement or it can be located separately in a post-plasma stage. In a one-stage arrangement, the catalyst is in direct contact with the electrical discharge plasma, which contains a variety of reactive species, which can be both short-lived and long-lived, such as excited-state atoms and molecules, radicals, photons, and energetic electrons. In comparison, in a two-stage arrangement, the catalyst is only exposed to long-lived reactive species, namely ozone and, possibly, vibrationally excited species [11].

Among the catalysts that are widely used, iron oxide $\left(\mathrm{Fe}_{2} \mathrm{O}_{3}\right)$ has been reported to be superior to the other transition metal oxides for the plasma-driven catalysis of the oxidation of diesel particulate matter [12,13]. Besides, manganese oxides (e.g., $\mathrm{MnO}_{2}$ ) were also widely investigated in combination with NTP in both one- and two-stage arrangements for VOC abatement [14-16]. Manganese-based catalysts were proven capable of effectively decomposing ozone to form atomic oxygen, which plays a key role in the oxidation of VOCs [17-19]. Recently, the use of bimetallic Mn-Fe catalysts has gained attraction due to their excellent activity for ozone decomposition [20,21]. Hence, the one-stage combination of NTP with a catalyst that either possesses good oxidative activity or superior ozone destruction capabilities is expected to promote VOC abatement. In this regard, the synergistic effects of plasma and supported catalysts, such as $\mathrm{Pt}, \mathrm{TiO}_{2}, \mathrm{MnO}_{x}$, and $\mathrm{CoO}_{x}$, have been observed in previous studies [22-25].

In this work, diethylether (DEE), an odorous and highly volatile organic compound, was chosen as a model VOC. The study aimed to investigate the decomposition of DEE using NTP combined with different cordierite honeycomb-supported catalysts, including Fe, Mn, and mixed Mn-Fe oxides. The use of cordierite honeycomb as a catalyst support does not cause a significant pressure drop across the reactor, which is meaningful from a practical viewpoint. A one-stage arrangement was used to examine the performance of the catalysts in terms of the decomposition of DEE in relation to their catalytic activities toward ozone decomposition. Based on the results that were obtained, a hybrid reactor combining one- and two-stage arrangements was proposed with the aim of enhancing catalyst performance with respect to DEE decomposition and optimizing energy efficiency. 


\section{Results and Discussion}

\subsection{X-ray Diffraction (XRD) Characterization of Prepared Catalysts}

The powder XRD patterns for both the bare cordierite and cordierite-supported catalysts are shown in Figure 1. As can be seen, the separate introduction of the manganese and iron oxides into cordierite led to the appearance of new diffraction peaks. For Fe/cordierite, several peaks were observed at $2 \theta$, namely at $24.0^{\circ}, 33.0^{\circ}$, and $35.6^{\circ}$, and were assigned to the formation of $\alpha-\mathrm{Fe}_{2} \mathrm{O}_{3}$ [26]. A new peak that appeared at $32.8^{\circ}$ for $\mathrm{Mn} /$ cordierite was attributed to the presence of $\mathrm{Mn}_{2} \mathrm{O}_{3}$. Other peaks of this phase (e.g., at $38.3^{\circ}$ and $55.2^{\circ}$ ) overlapped with those of the support [27]. Interestingly, the XRD pattern of cordierite did not exhibit any changes after co-impregnation of the two metal oxides. This observation suggested a strong interaction between the Mn and Fe species, which likely existed as an amorphous mixed oxide. A similar result was reported by Lian et al. for a bimetallic $\mathrm{Mn}-\mathrm{Fe}$ catalyst prepared by a hydrothermal method [20].

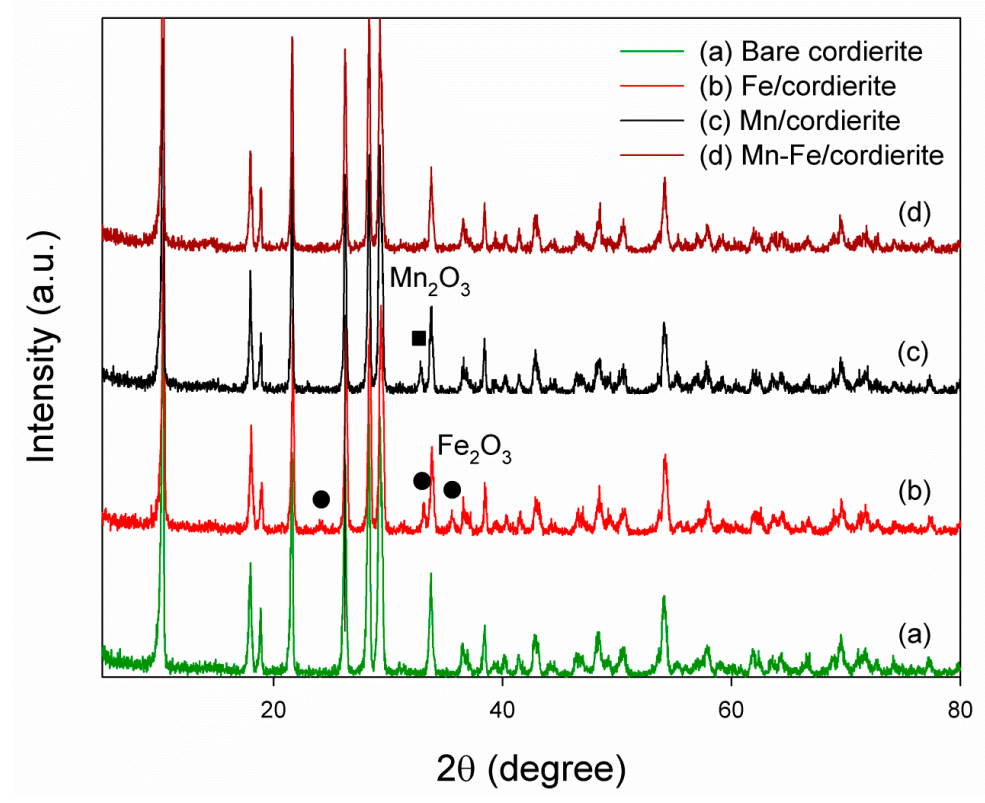

Figure 1. Powder XRD patterns of bare and coated cordierites.

\subsection{Catalytic Activities of Prepared Catalysts for Ozone Decomposition}

The catalytic activities of the prepared catalysts toward the decomposition of ozone generated in the air plasma were investigated and shown in Figure 2a. The preliminary experiment showed that the bare cordierite support did not show any activity for ozone decomposition. Meanwhile, all the prepared catalysts were observed to achieve a complete destruction of ozone early in the test. However, the performance of the catalysts subsequently decreased to different extents as a function of time-on-stream. Both the Mn and Fe-coated cordierites exhibited a drastic attenuation in their respective catalytic activities. Indeed, the ozone decomposition efficiency of Fe/cordierite reached zero after $6 \mathrm{~h}$, whereas that of Mn/cordierite was reduced to only $c a$. $20 \%$ during the same period of time. As expected, the behavior exhibited by $\mathrm{Mn}-\mathrm{Fe}$ /cordierite differed from those of the other catalysts. The ozone decomposition efficiency for the mixed oxide catalyst gently decreased to $c a .89 \%$ after $3 \mathrm{~h}$, which exceeded the simple sum of those of 
the monometallic catalysts. This result clearly showed the synergistic effect of $\mathrm{Mn}$ and $\mathrm{Fe}$ on the decomposition of ozone. The low crystallinity of the Mn-Fe mixed oxide, as observed by XRD, which indicated more defects and possibly an enhanced surface area, is believed to favor the decomposition of ozone [20].
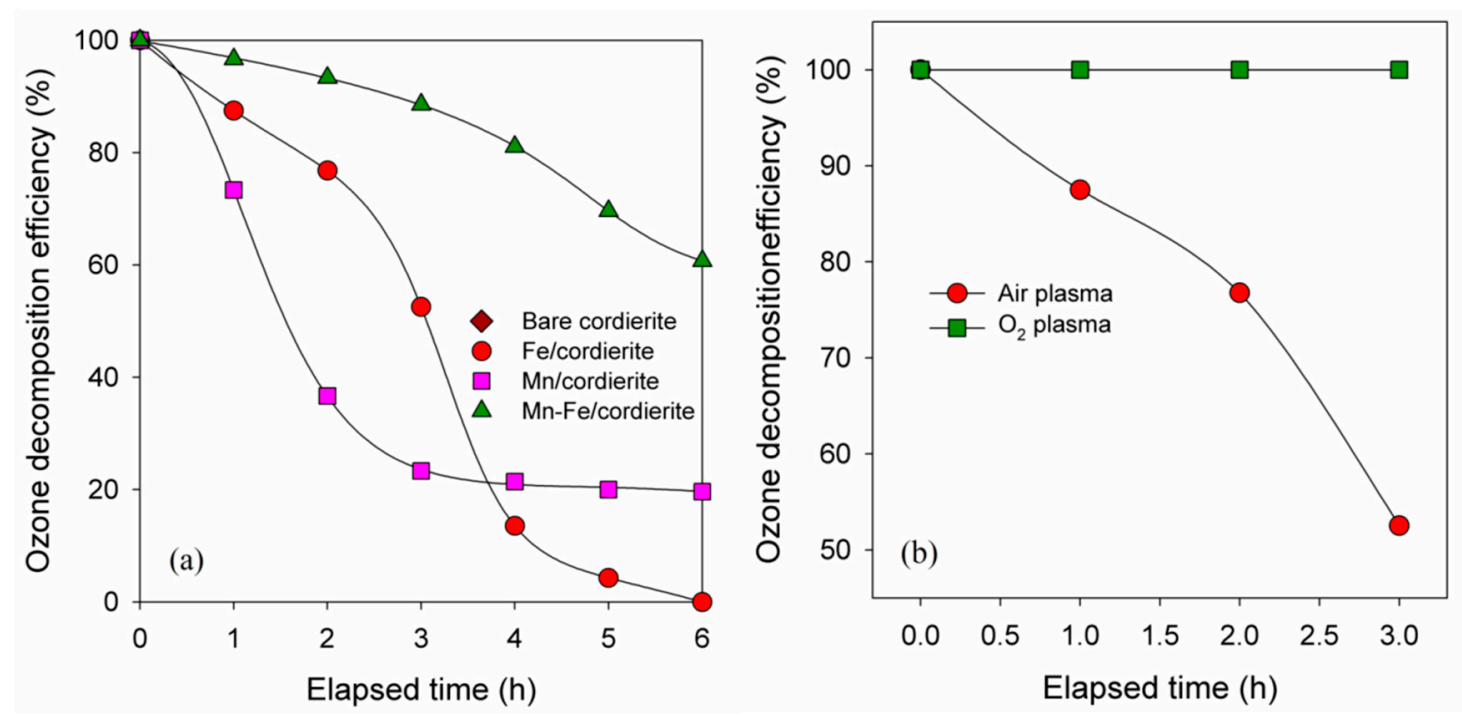

Figure 2. (a) Ozone decomposition efficiency of prepared catalysts with air plasma (initial ozone concentration: $300 \mathrm{ppm}$ ); (b) Ozone decomposition efficiency of Fe/cordierite with oxygen plasma (initial ozone concentration: $300 \mathrm{ppm}$ ).

The deactivated $\mathrm{Fe} /$ cordierite was then regenerated at $250{ }^{\circ} \mathrm{C}$ for $1.0 \mathrm{~h}$ in ambient air to continue investigating the catalyst performance toward ozone decomposition in the presence of oxygen plasma. As shown in Figure 2b, Fe/cordierite recovered its catalytic activity after the thermal treatment. In contrast to its behavior in the presence of air-generated ozone, catalyst deactivation was not observed during $3.0 \mathrm{~h}$ with oxygen plasma. The nitrogen oxides $\left(\mathrm{NO}_{x}\right)$ that formed in the air plasma were thus considered to be responsible for the degradation of the catalysts. The strong adsorption of $\mathrm{NO}_{x}$ resulted in a blockage of the active sites that were used for ozone decomposition. In our preliminary experiment, the $\mathrm{Fe} /$ cordierite could not be regenerated below a temperature of $150{ }^{\circ} \mathrm{C}$. Hence, the selection of an ozone decomposition catalyst with a long-term stability at low temperature should be considered, especially for the two-stage arrangement. The use of oxygen plasma is ineffective unless a cyclic treatment (i.e., VOC adsorption followed by oxygen plasma oxidation) is applied [28,29].

Samples of $\mathrm{Fe} /$ cordierite were collected before and after the ozone decomposition test (with air plasma), after which they were powdered, thoroughly mixed with $\mathrm{KBr}$, and then pelletized for Fourier transform infrared (FTIR) characterization. As shown in Figure 3, the FTIR spectrum of the supported catalyst did not display any characteristic changes after the ozone decomposition reaction, except for a peak that appeared at a wavenumber of $1385 \mathrm{~cm}^{-1}$, which confirmed the presence of nitrate species $\left(\mathrm{NO}_{3}{ }^{-}\right)$that formed according to the following reactions [30]:

$$
\begin{gathered}
3 \mathrm{NO}_{2}+\mathrm{O}_{2}^{-}(\text {surf }) \rightarrow 2 \mathrm{NO}_{3}^{-}(\text {ads })+\mathrm{NO} \\
2 \mathrm{NO}_{2}+\mathrm{O}_{2}^{-}(\text {surf }) \rightarrow \mathrm{NO}_{3}^{-}(\text {ads })+\mathrm{NO}_{2}^{-}(\text {ads })
\end{gathered}
$$




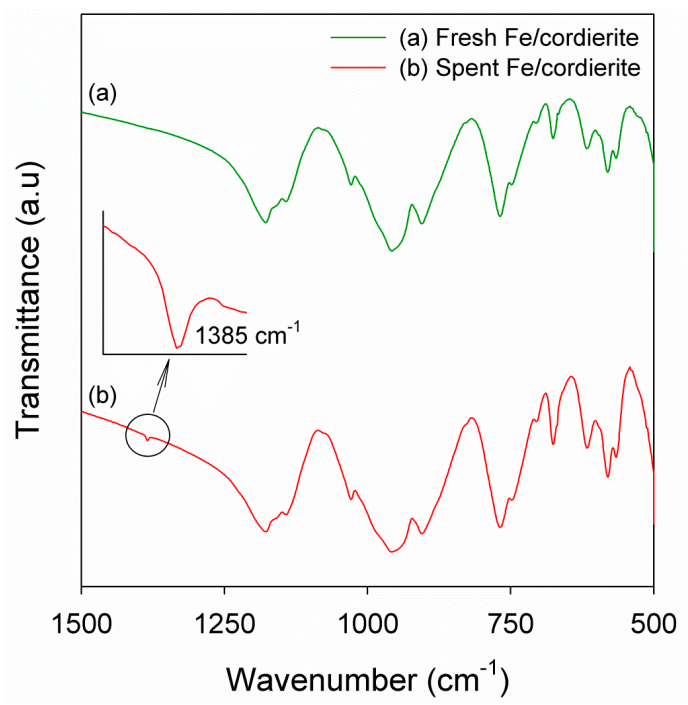

Figure 3. FTIR spectra of Fe/cordierite before and after ozone decomposition with air plasma.

\subsection{DEE Decomposition in a One-Stage Reactor}

The decomposition efficiency of DEE in the one-stage reactor containing different catalysts is shown in Figure 4. For comparison purposes, the experiment was also performed with the blank dielectric barrier discharge (DBD) reactor. Generally, in all of the cases, the DEE removal rate increased as the specific input energy (SIE) was increased. Here, SIE was defined by the discharge power determined from the Lissajous figure divided by the flow rate. For the blank reactor, ca. $71 \%$ of DEE conversion was obtained at an SIE of $c a$. $618 \mathrm{~J} \mathrm{~L}^{-1}$, a result which was in good agreement with a previous report, which described the energy efficiency for DEE decomposition using a double dielectric barrier discharge (DDBD) reactor [8]. The introduction of cordierite honeycomb into the plasma appeared to improve the destruction of DEE, especially for low amounts of SIE. The improvement was probably due to the modification of plasma discharge and the extension of the DEE residence time. Unexpectedly, the separate incorporation of $\mathrm{Fe}$ and $\mathrm{Mn}$ into the cordierite did not lead to any further improvement in the DEE decomposition, indicating that, in this case, most of the DEE was destroyed by the plasma. Therefore, in the three particular cases, $c a .96 \%$ of DEE was removed from the gas stream at an SIE of $c a .600 \mathrm{~J} \mathrm{~L}^{-1}$. Jo et al. also reported a similar result for the plasma-catalytic decomposition of ethylene using bare and $\mathrm{MnO}_{2}$-coated alumina ceramic membranes [31]. Even worse, the bimetallic $\mathrm{Mn}-\mathrm{Fe} /$ cordierite catalyst lowered the DEE decomposition efficiency by more than $15 \%$ across the whole range of SIEs that were used. Raising the SIE beyond this range to $900 \mathrm{~J} \mathrm{~L}^{-1}$ resulted in only a ca. $90 \%$ of DEE conversion.

Figure 5 shows the outlet ozone concentration during the decomposition of DEE in the one-stage reactor as a function of the SIE for the different catalysts. For comparison, the ozone concentration of the blank reactor is also included. At low SIE, the presence of the bare and Fe coated cordierites resulted in the formation of more ozone probably by enhancing the local electric field near the catalyst surfaces. As opposed to its reduced ability to affect DEE decomposition, the catalytic activity of the $\mathrm{Mn}-\mathrm{Fe} /$ cordierite was observed to exceed those obtained using the other methods for ozone decomposition under plasma activation. The ozone concentration of $\mathrm{Mn}-\mathrm{Fe} /$ cordierite was saturated at only $220 \mathrm{ppm}$, while the saturation values obtained otherwise ranged to above $600 \mathrm{ppm}$. This behavior was similar to that observed in the ozone decomposition test (shown in section 2.2). Thus, the one-stage combination of plasma with a 
well-performing ozone decomposition catalyst (i.e., Mn-Fe/cordierite) did not prove advantageous for the removal of DEE. It seemed that under plasma activation, Mn-Fe/cordierite accelerated the decomposition of $\mathrm{O}_{3}$ to $\mathrm{O}_{2}$, in that the adsorbed $\mathrm{O} \cdot$ radicals that formed were not mainly consumed during the oxidation of DEE. As proposed by Li and Oyama [32], the decomposition of ozone is initiated by the dissociative adsorption of ozone to form an oxygen molecule and an atomic oxygen species, which in turn reacts with ozone to finally form molecular oxygen. The mechanism is summarized as follows:

$$
\begin{gathered}
\mathrm{O}_{3}+* \rightarrow \mathrm{O}_{2}+\mathrm{O}^{*} \\
\mathrm{O}_{3}+\mathrm{O}^{*} \rightarrow \mathrm{O}_{2}+\mathrm{O}_{2} * \\
\mathrm{O}_{2}^{*} \rightarrow \mathrm{O}_{2}{ }^{*}
\end{gathered}
$$

where the ${ }^{*}$ symbol represents an active site. Through reaction (4), the ozone that effectively formed near the catalyst surface might compete with the DEE for atomic oxygen. The low DEE decomposition efficiency with $\mathrm{Mn}-\mathrm{Fe} /$ cordierite suggested that in plasma, besides active short-lived species, ozone itself played a significant role in the reaction of DEE.

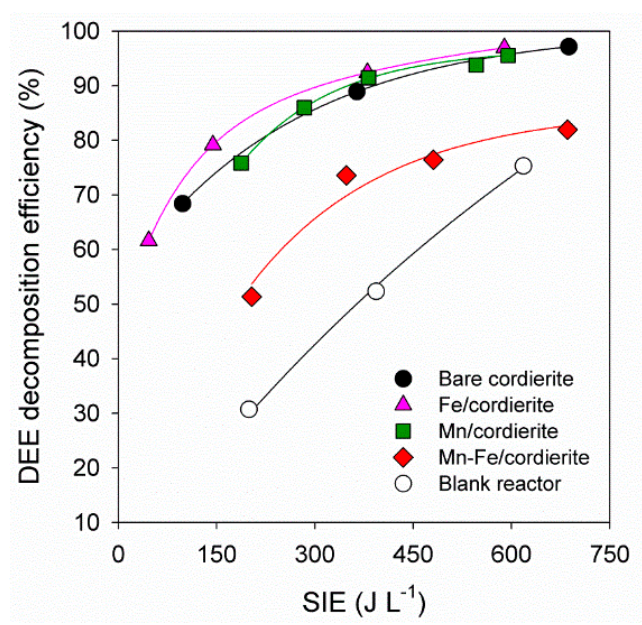

Figure 4. DEE decomposition efficiency in a one-stage reactor with different catalysts.

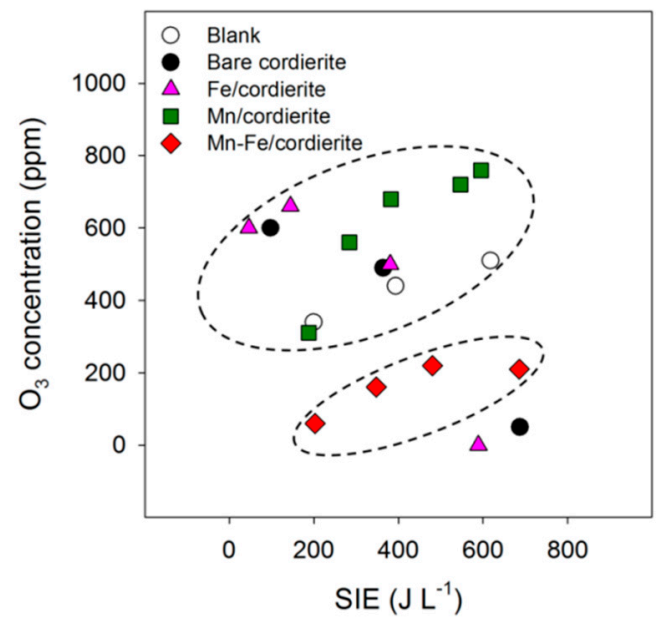

Figure 5. Outlet ozone concentration during decomposition of DEE in one-stage reactor. 
In an earlier study, Ogata et al. [33] also reported that the use of a $\mathrm{Cu}-\mathrm{Cr}$ catalyst to dissociate ozone into active atomic oxygen species was not effective for the reaction under plasma discharge, for which the extent of the decomposition of toluene and dichloromethane in a one-stage reactor was almost the same or even worse (for an increasing amount of catalyst) than in a conventional plasma reactor. These authors concluded that, for the single-stage combination (i.e., the one-stage arrangement), the ozone decomposition property of the catalysts was not important. Similarly, Van Durme et al. [34] found that when $\mathrm{MnO}_{2}-\mathrm{CuO} / \mathrm{TiO}_{2}$ was subjected to a plasma, it resulted in a low toluene removal efficiency compared to $\mathrm{TiO}_{2}$, which does not have the ability to decompose ozone. However, a positive effect was observed for the in-plasma supported $\mathrm{MnO}_{x}$ catalyst when dealing with acetone, a persistent compound [16,30], in which case the formation of ozone-induced atomic oxygen therefore becomes important. It is noted that, unlike acetone, the above VOCs (e.g., ethylene, diethyl ether, and toluene) are more reactive with ozone. The gas-phase reaction of ozone with toluene, for example, is slow; however, in the presence of plasma discharge, ozone could be excited, whereby its activity increased [35,36]. The destruction of vibrationally excited ozone, generated by a three-body reaction, was reported to be about 1600 times faster than ground-state ozone due to collisions with oxygen atoms $[37,38]$.
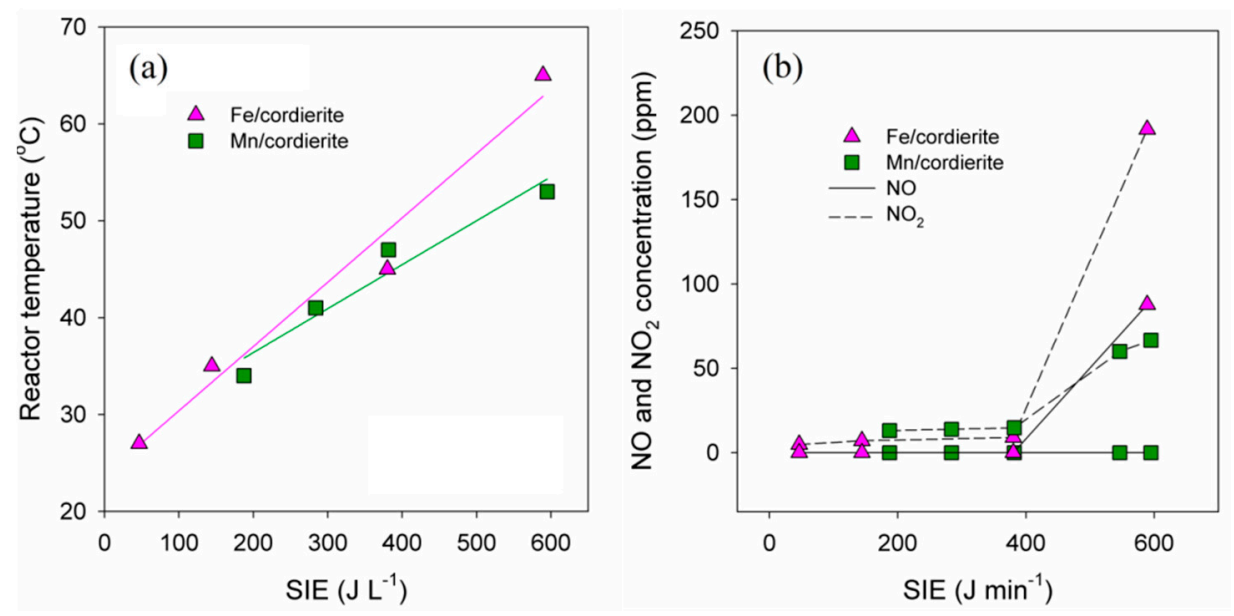

Figure 6. (a) Temperature and (b) $\mathrm{NO}$ and $\mathrm{NO}_{2}$ concentrations of one-stage reactor with $\mathrm{Fe}$ and Mn coated cordierites.

Interestingly, the ozone concentrations of the bare and Fe-coated cordierites reached almost zero at a high SIE of $c a$. $600 \mathrm{~J} \mathrm{~L}^{-1}$. In our preliminary experiment, ozone was only significantly decomposed in the gas phase above $150{ }^{\circ} \mathrm{C}$; however, as seen in Figure $6 \mathrm{a}$, the reactor temperature did not exceed $70{ }^{\circ} \mathrm{C}$, indicating the negligible thermal decomposition of ozone. The occurrence of a zero ozone concentration at high input energies was also reported elsewhere [33,39]. It was proposed that $\mathrm{O}_{3}$ is consumed by $\mathrm{NO}$, which is favorably formed at high SIE values to produce $\mathrm{NO}_{2}$, which subsequently reacts with atomic oxygen to regenerate $\mathrm{NO}[40,41]$. The catalytic cycle for $\mathrm{O}_{3}$ destruction by $\mathrm{NO}_{x}$ is described as follows:

$$
\begin{aligned}
& \mathrm{NO}+\mathrm{O}_{3} \rightarrow \mathrm{NO}_{2}+\mathrm{O}_{2} \\
& \mathrm{NO}_{2}+\mathrm{O} \rightarrow \mathrm{NO}+\mathrm{O}_{2}
\end{aligned}
$$


The net reaction can be written as

$$
\mathrm{O}_{3}+\mathrm{O} \rightarrow \mathrm{O}_{2}+\mathrm{O}_{2}
$$

The concentrations of $\mathrm{NO}_{x}$ at the outlet of the one-stage reactor for the $\mathrm{Mn}$ and $\mathrm{Fe}$ coated cordierites were measured during plasma-catalytic oxidation of DEE. As can be seen in Figure 6b, NO was not detected within the investigated range of SIE for $\mathrm{Mn}$ /cordierite but appeared at above $400 \mathrm{~J} \mathrm{~L}^{-1}$ for the $\mathrm{Fe} /$ cordierite. Meanwhile, the formation of $\mathrm{NO}_{2}$ slowly took place at SIE below $400 \mathrm{~J} \mathrm{~L}^{-1}$ for both catalysts and then steeply increased as further raising SIE, especially for the Fe/cordierite. At the SIE of ca. $590 \mathrm{~J} \mathrm{~L}^{-1}$, the $\mathrm{NO}_{2}$ concentration obtained with the Fe/cordierite reached $c a .190 \mathrm{ppm}$, while that of the $\mathrm{Mn} /$ cordierite was only $c a$. $60 \mathrm{ppm}$. The concentration of $\mathrm{NO}$ was much less than that of $\mathrm{NO}_{2} \mathrm{because}$ $\mathrm{NO}$ rapidly reacted with ozone (reaction (6)) and atomic oxygen (reaction (9)) to form $\mathrm{NO}_{2}$.

$$
\mathrm{NO}+\mathrm{O} \rightarrow \mathrm{NO}_{2}
$$

The regeneration of $\mathrm{NO}$ from $\mathrm{NO}_{2}$ through reaction (7) was relatively slow. The behaviors of the two catalysts for the formation of $\mathrm{NO}_{x}$ were in contrast to their effects on the $\mathrm{O}_{3}$ concentration at high SIE shown in Figure 5, indicating that $\mathrm{NO}_{x}$ played significant roles in the suppression of $\mathrm{O}_{3}$ formation.

Our results indicated that it is possible to improve the performance of the reactor by using a hybrid reactor containing $\mathrm{Mn} /$ cordierite in the plasma and $\mathrm{Mn}$-Fe/cordierite in the post-plasma stage. This reactor, henceforth denoted as the $\mathrm{Mn}+(\mathrm{Mn}-\mathrm{Fe})$ reactor, was proposed for further experiments, in which the post-plasma catalyst bed was retained at room temperature.

\subsection{DEE Decomposition in the $M n+(M n-F e)$ Reactor}

As seen in Figure 7, the efficiency of the DEE decomposition increased by more than $10 \%$ compared to that without $\mathrm{Mn}-\mathrm{Fe} /$ cordierite at SIE values below $300 \mathrm{~J} \mathrm{~L}^{-1}$, after which saturation occurred at around $99 \%$. Thus, an appropriate combination of plasma with the two Mn-based catalysts resulted in an obvious improvement of the reactor performance in terms of both DEE conversion and energy consumption. The ozone that formed during plasma discharge and its catalytic dissociation to produce atomic oxygen in the post-plasma was therefore effective for achieving the oxidation of DEE. The hybrid combination also substantially diminished the emission of ozone, a toxic gas, to levels below 200 ppm (Figure 8). Additionally, it is shown in Figure 7 that the hybrid reactor was also more efficient than the two-stage reactor with $\mathrm{Mn}-\mathrm{Fe} /$ cordierite as the post-plasma catalyst, especially at low values of SIE. The result came from the advantage of the in-plasma catalysts, which probably altered the plasma discharge mode and enhanced the residence time of gaseous species.

The concentrations of carbon oxides $\left(\mathrm{CO}\right.$ and $\left.\mathrm{CO}_{2}\right)$ that were detected during DEE decomposition in the $\mathrm{Mn}+(\mathrm{Mn}-\mathrm{Fe})$ reactor are shown in Figure 9. The amount of $\mathrm{CO}_{2}$ increased almost linearly as the SIE was increased, whereas that of $\mathrm{CO}$ tended to rise exponentially to a maximum within the SIE range. These trends were also observed in previous studies, thereby implying a high degree of oxidation of VOCs to $\mathrm{CO}_{2}$, which is favored at high SIEs [16,31]; that is, ca. 89\% of DEE was oxidatively transformed to carbon oxides at around $600 \mathrm{~J} \mathrm{~L}^{-1}$. 


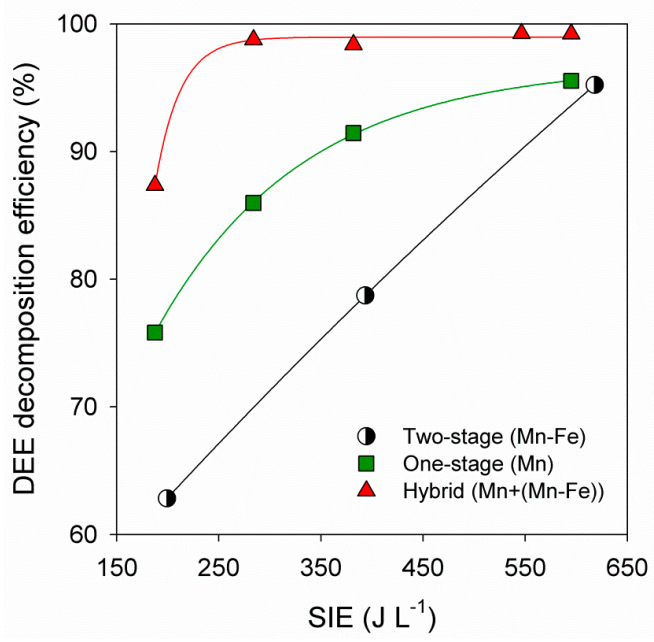

Figure 7. DEE decomposition efficiency of hybrid $\mathrm{Mn}+(\mathrm{Mn}-\mathrm{Fe})$ reactor, one-stage reactor with $\mathrm{Mn} /$ cordierite, and two-stage reactor with $\mathrm{Mn}-\mathrm{Fe} /$ cordierite.

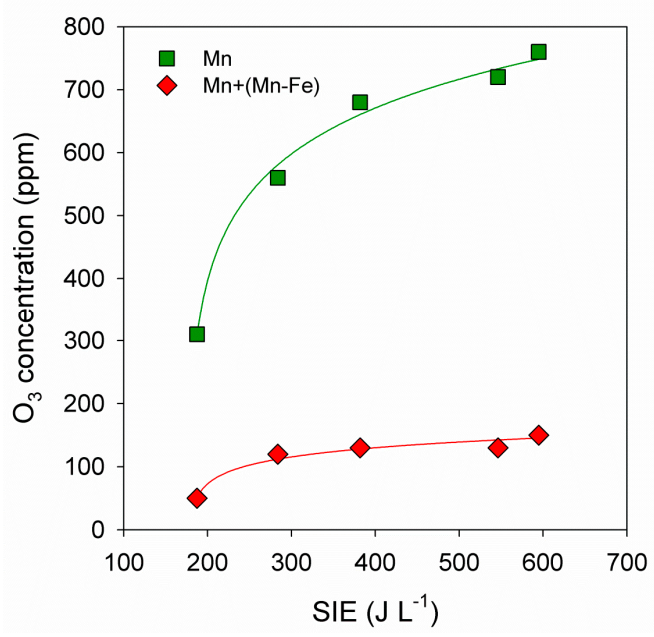

Figure 8. Outlet ozone concentration of hybrid $\mathrm{Mn}+(\mathrm{Mn}-\mathrm{Fe})$ reactor and one-stage reactor with $\mathrm{Mn} /$ cordierite catalyst.

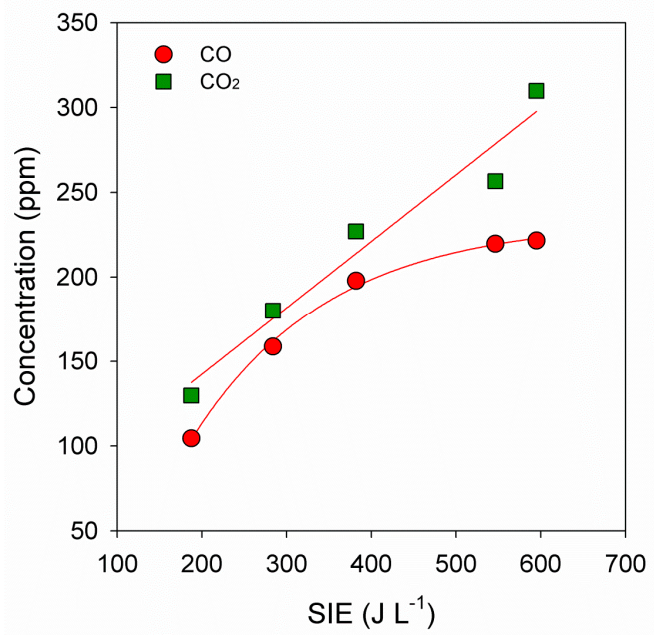

Figure 9. Concentrations of carbon oxides during DEE decomposition in hybrid $\mathrm{Mn}+(\mathrm{Mn}-\mathrm{Fe})$ reactor. 
The stabilities of catalysts used in the $\mathrm{Mn}+(\mathrm{Mn}-\mathrm{Fe})$ reactor were judged in terms of $\mathrm{DEE}$ decomposition efficiency and outlet ozone concentration at SIEs of $c a .382 \mathrm{~J} \mathrm{~L}^{-1}$. In Figure 10, it can be seen that there was no decline in the DEE decomposition efficiency during the course of the experiment. The outlet ozone concentration, however, increased with time-on-stream and reached a steady-state at $180 \mathrm{ppm}$ after $5 \mathrm{~h}$. This indicated that the unreacted DEE and oxidation products, such as $\mathrm{CO}_{x}, \mathrm{H}_{2} \mathrm{O}$, and the intermediates that had reversibly adsorbed on $\mathrm{Mn}-\mathrm{Fe} /$ cordierite, could partially inhibit $\mathrm{NO}_{x}$ adsorption, thereby slowing down the catalyst deactivation.

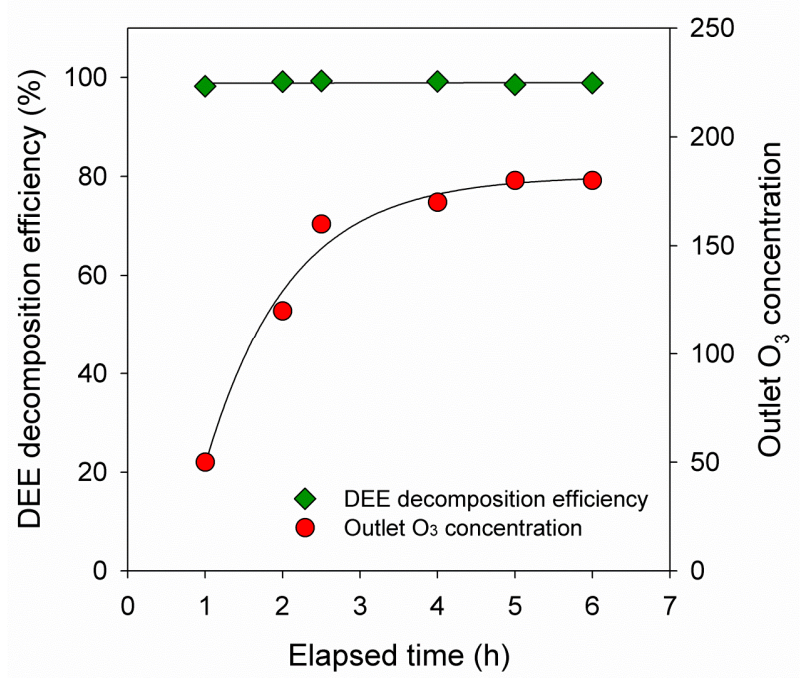

Figure 10. DEE decomposition efficiency and outlet ozone concentration of hybrid $\mathrm{Mn}+(\mathrm{Mn}-\mathrm{Fe})$ reactor at a SIE of $382 \mathrm{~J} \mathrm{~L}^{-1}$.

\section{Experimental Section}

\subsection{Apparatus and Materials}

The experimental reactor system is schematically shown in Figure 11. The DBD reactor consisted of a dielectric quartz tube (inner diameter: $26 \mathrm{~mm}$, thickness: $4 \mathrm{~mm}$ ) wrapped in aluminum foil (length: $70 \mathrm{~mm}$ ) to act as a ground electrode. A copper wire (diameter: $1 \mathrm{~mm}$ ) coaxially inserted into the quartz tube served as a high voltage (HV) electrode, resulting in a $12.5 \mathrm{~mm}$ discharge gap and a $70 \mathrm{~mm}$ discharge length. In preparation for the DEE removal test, a one-stage reactor was constructed by placing the cordierite-supported catalysts directly inside the discharge region of the DBD reactor (Figure 11a). The plasma was ignited by using an alternating current (AC) power source at a fixed frequency of $400 \mathrm{~Hz}$. In preparation for the examination of the catalytic activity toward ozone decomposition, the catalysts under investigation were placed downstream from the blank DBD reactor (i.e., similar to a two-stage arrangement, Figure 11b). This arrangement allowed for the initial generation of ozone in the plasma reactor, after which it would be transferred with either an air or an oxygen stream to be subsequently decomposed over the catalyst bed at room temperature. The hybrid $\mathrm{Mn}+(\mathrm{Mn}-\mathrm{Fe})$ reactor containing $\mathrm{Mn} /$ cordierite in plasma region and $\mathrm{Mn}-\mathrm{Fe} /$ cordierite in post-plasma region for decomposition of DEE is schematically shown in Figure 11c.

The catalyst support had a cylindrical shape (diameter: $26 \mathrm{~mm}$, length: $70 \mathrm{~mm}$, weight: $15.5 \mathrm{~g}$ ) and was cut from a commercial cordierite monolith (diameter: $144 \mathrm{~mm}$, high: $152 \mathrm{~mm}, 400$ cells per square 
inch). Different catalysts including $\mathrm{Mn}, \mathrm{Fe}$, and mixed Mn-Fe oxides were prepared by a dip-coating method using $\mathrm{Mn}\left(\mathrm{NO}_{3}\right)_{2} .6 \mathrm{H}_{2} \mathrm{O}$ (Junsei Chemical, Tokyo, Japan) and $\mathrm{Fe}\left(\mathrm{NO}_{3}\right)_{3} .9 \mathrm{H}_{2} \mathrm{O}$ (Daejung Chemicals \& Metals, Shiheung, Korea) as metal precursors. The Mn-Fe catalyst was prepared by using a mixture of the two nitrates. The cordierite support was dipped into the respective aqueous nitrate solution at room temperature and then dried overnight at $110{ }^{\circ} \mathrm{C}$, before it was calcinated at $500{ }^{\circ} \mathrm{C}$ for $3 \mathrm{~h}$. The dipping step was repeated several times before calcination. Finally, cordierite-supported $\mathrm{Mn}$ (1.7 wt.\%), Fe (1.6 wt.\%), and Mn-Fe (1.5-1.5 wt.\%) catalysts, denoted as Mn/cordierite, Fe/cordierite, and $\mathrm{Mn}-\mathrm{Fe} /$ cordierite, respectively, were obtained. The weight percentages of the active components were estimated from the amount of solution that was adsorbed on the cordierite supports.

The concentration of the DEE in the gas (synthetic dry air: $21 \% \mathrm{O}_{2}$ and $79 \% \mathrm{~N}_{2}$, by volume) and the flow rate were controlled at $150 \mathrm{ppm}$ and $1.0 \mathrm{~L} \mathrm{~min}^{-1}$, respectively, by using mass flow controllers (MFC). For the ozone decomposition test, either synthetic dry air or pure oxygen (without DEE) was fed into the reactor at a flow rate of $1.0 \mathrm{~L} \mathrm{~min}^{-1}$ and the ozone concentration was maintained at $300 \mathrm{ppm}$ in both of these cases. All catalysts were thermally treated at $450{ }^{\circ} \mathrm{C}$ for $1 \mathrm{~h}$ in ambient air before each experiment, unless otherwise noted.

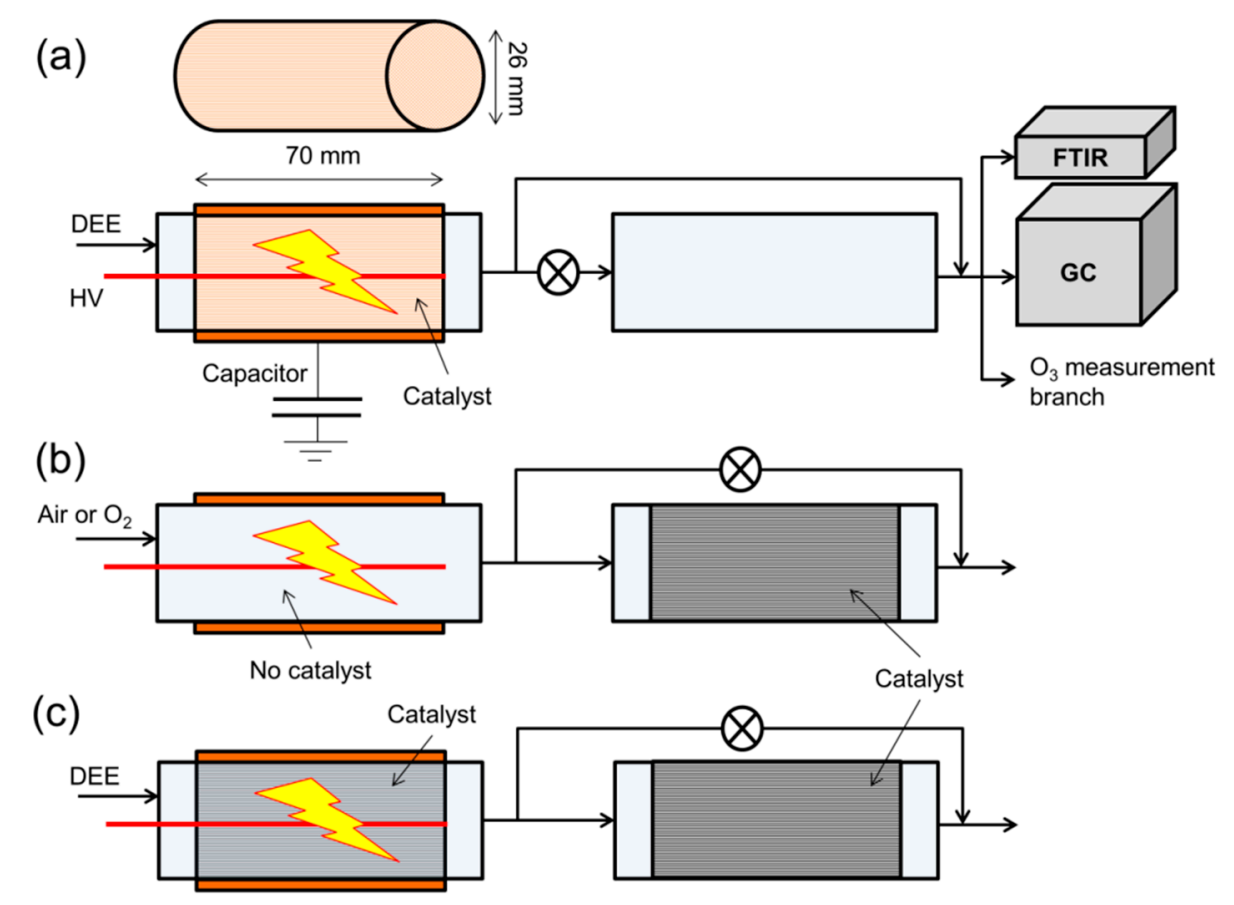

Figure 11. Experimental reactor system. (a) One-stage reactor for DEE decomposition, (b) Reactor for investigating ozone decomposition on different catalysts and (c) Hybrid $\mathrm{Mn}+(\mathrm{Mn}-\mathrm{Fe})$ reactor for DEE decomposition.

\subsection{Measurement Methods}

The concentration of DEE was monitored using a gas chromatograph (Bruker 450-GC) equipped with a flame ionization detector (FID) and a $60 \mathrm{~m} \times 0.32 \mathrm{~mm}$ BR-624ms capillary column. The oven temperature was ramped from 50 to $60{ }^{\circ} \mathrm{C}$ at a rate of $1.0^{\circ} \mathrm{C} \mathrm{min}{ }^{-1}$. FTIR spectroscopy (IRPrestige-21, Shimadzu) with a $76 \mathrm{~mm}$-long gas cell was used to measure concentrations of carbon oxides and nitrogen oxides formed during the oxidation of DEE. All samples were collected at a resolution of $2.0 \mathrm{~cm}^{-1}$ with 
20 scans. The ozone concentration was measured by using a portable gas analyzer (PortaSens II, Analytical Technology). Reactor temperature measurements were performed by using an ethanol thermometer positioned $5 \mathrm{~mm}$ downstream from the discharge region. The experimental data were recorded 20 min after plasma ignition, unless otherwise noted.

Charge dissipation in the DBD reactor was measured by measuring the voltage drop on a capacitor (capacitance: $1.0 \mu \mathrm{F}$ ) that was connected in series to the reactor. Details of the voltage measurement are described elsewhere [29]. The discharge power was calculated from the so-called voltage-charge Lissajous figures.

The prepared catalysts were characterized by FTIR spectroscopy and an XRD system (D/MAX2200H, Bede 200, Rigaku instruments) equipped with $\mathrm{Cu} \mathrm{K \alpha}$ radiation (40 kV, $40 \mathrm{~mA})$.

\section{Conclusions}

The decomposition of DEE using NTP combined with cordierite-supported $\mathrm{Mn}, \mathrm{Fe}$, and mixed $\mathrm{Mn}-\mathrm{Fe}$ oxides was investigated in this work. It was found that, for the one-stage experimental arrangement, most of the DEE was destroyed by the plasma, because the incorporation of either Mn oxide or Fe oxide in the cordierite did not lead to a significant improvement in the removal of the DEE. Of all the catalysts that were tested, Mn-Fe/cordierite, the catalyst that was most efficient at decomposing ozone, was found to lower the DEE decomposition efficiency. Thus, the catalytic activity for ozone decomposition under plasma discharge conditions was such that DEE removal could not be achieved. However, Mn-Fe/cordierite was able to catalyze the ozonation of unreacted DEE when it was placed downstream from the $\mathrm{Mn}$ /cordierite reactor in which the plasma discharge occurred, enhancing the reactor performance in terms of DEE decomposition and energy efficiencies as well as reducing ozone emission.

\section{Acknowledgments}

This work was supported by the R\&D Program of "Plasma Advanced Technology for Agriculture and Food (Plasma Farming)" through the National Fusion Research Institute of Korea (NFRI), and by the Cooperative Research Program for Agriculture, Science \& Technology Development (Project No. PJ008508032012), Rural Development Administration, Korea.

\section{Author Contributions}

Quang Hung Trinh carried out the experimental work and analyzed the data; Young Sun Mok supervised all of the study.

\section{Conflicts of Interest}

The authors declare no conflict of interest.

\section{References}

1. Yamamoto, T. VOC decomposition by nonthermal plasma processing-a new approach. J. Electrostat. 1997, 42, 227-238. 
2. Roland, U.; Holzer, F.; Kopinke, F.-D. Improved oxidation of air pollutants in a non-thermal plasma. Catal. Today 2002, 73, 315-323.

3. Mista, W.; Kacprzyk, R. Decomposition of toluene using non-thermal plasma reactor at room temperature. Catal. Today 2008, 137, 345-349.

4. Schmid, S.; Jecklin, M.C.; Zenobi, R. Degradation of volatile organic compounds in a non-thermal plasma air purifier. Chemosphere 2010, 79, 124-130.

5. Abd Allah, Z.; Whitehead, J.C.; Martin, P. Remediation of dichloromethane $\left(\mathrm{CH}_{2} \mathrm{Cl}_{2}\right)$ using non-thermal, atmospheric pressure plasma generated in a packed-bed reactor. Environ. Sci. Technol. 2013, 48, 558-565.

6. Demidiouk, V.; Chae, J.O. Decomposition of volatile organic compounds in plasma-catalytic system. IEEE Trans. Plasma Sci. 2005, 33, 157-161.

7. Zhu, T.; Li, J.; Jin, Y.; Liang, Y.; Ma, G. Decomposition of benzene by non-thermal plasma processing: Photocatalyst and ozone effect. Int. J. Environ. Sci. Tech. 2008, 5, 375-384.

8. Chae, J.; Moon, S.; Sun, H.; Kim, K.; Vassiliev, V.A.; Mikholap, E.M. A study of volatile organic compounds decomposition with the use of non-thermal plasma. KSME Int. J. 1999, 13, 647-655.

9. Kim, H.H.; Ogata, A. Nonthermal plasma activates catalyst: from current understanding and future prospects. Eur. Phys. J. Appl. Phys. 2011, 55, 13806.

10. Kim, H.H.; Ogata, A. Interaction of nonthermal plasma with catalyst for the air pollution control. Int. J. Plasma Environ. Sci. Technol. 2012, 6, 43-48.

11. Whitehead, J.C. Plasma catalysis: A solution for environmental problems. Pure Appl. Chem. 2010, 82, 1329-1336.

12. Yamamoto, S.; Yao, S.; Kodama, S.; Mine, C.; Fujioka, Y. Investigation of transition metal oxide catalysts for diesel PM removal under plasma discharge conditions. Open Catal. J. 2008, 1, $11-16$.

13. Yao, S.; Yamamoto, S.; Kodama, S.; Mine, C.; Fujioka, Y. Characterization of catalyst-supported dielectric barrier discharge reactor. Open Catal. J. 2009, 2, 79-85.

14. Zhu, T.; Wan, Y.D.; Li, J.; He, X.W.; Xu, D.Y.; Shu, X.Q.; Liang, W.J.; Jin, Y.Q. Volatile organic compounds decomposition using nonthermal plasma coupled with a combination of catalysts. Int. J. Environ. Sci. Technol. 2011, 8, 621-630.

15. Chen, H.L.; Lee, H.M.; Chen, S.H.; Chang, M.B.; Yu, S.J.; Li, S.N. Removal of volatile organic compounds by single-stage and two-stage plasma catalysis systems: A review of the performance enhancement mechanisms, current status, and suitable applications. Environ. Sci. Technol. 2009, 43, 2216-2227.

16. Trinh, H.Q.; Mok, Y.S. Plasma-catalytic oxidation of acetone in annular porous monolithic ceramic-supported catalysts. Chem. Eng. J. 2014, 251, 199-206.

17. Einaga, H.; Ogata, A. Benzene oxidation with ozone over supported manganese oxide catalysts: effect of catalyst support and reaction conditions. J. Hazard. Mater. 2009, 164, 1236-41.

18. Ye, L.; Feng, F.; Liu, J.; Tang, X.; Zhang, X.; Huang, Y.; Liu, Z.; Yan, K. Toluene decomposition by a two-stage hybrid plasma catalyst system in dry air. IEEE Trans. Plasma Sci. 2014, 42, 3529-3538.

19. Jin, M.; Kim, J.H.; Kim, J.M.; Jeon, J.-K.; Jurng, J.; Bae, G.-N.; Park, Y.-K. Benzene oxidation with ozone over $\mathrm{MnO}_{x} / \mathrm{SBA}-15$ catalysts. Catal. Today 2013, 204, 108-113. 
20. Lian, Z.; Ma, J.; He, H. Decomposition of high-level ozone under high humidity over Mn-Fe catalyst: The influence of iron precursors. Catal. Commun. 2015, 59, 156-160.

21. Zaloznaya, L.A.; Tkachenko, S.N.; Egorova, G.V.; Tkachenko, I.S.; Sobolev, A.V.; Golosman, E.Z.; Troshina, V.A.; Lunin, V.V. Ozone decomposition and benzene oxidation catalysts based on iron and manganese oxides as industrial wastes from water decontamination by ozone treatment. Catal. Ind. 2009, 1, 224-228.

22. Demidiouk, V.; Moon, S.; Chae, J.; Lee, D. Application of a plasma-catalytic system for decomposition of volatile organic compounds. J. Korean Phys. Soc. 2003, 42, 966-970.

23. Futamura, S.; Einaga, H.; Kabashima, H.; Hwan, L.Y. Synergistic effect of silent discharge plasma and catalysts on benzene decomposition. Catal. Today 2004, 89, 89-95.

24. Ayrault, C.; Barrault, J.; Blin-Simiand, N.; Jorand, F.; Pasquiers, S.; Rousseau, A.; Tatibouët, J.M. Oxidation of 2-heptanone in air by a DBD-type plasma generated within a honeycomb monolith supported Pt-based catalyst. Catal. Today 2004, 89, 75-81.

25. Subrahmanyam, C.; Renken, A.; Kiwi-Minsker, L. Novel catalytic dielectric barrier discharge reactor for gas-phase abatement of isopropanol. Plasma Chem. Plasma Process. 2006, 27, 13-22.

26. Jaafar, N.F.; Abdul Jalil, A.; Triwahyono, S.; Muhd Muhid, M.N.; Sapawe, N.; Satar, M.A.H.; Asaari, H. Photodecolorization of methyl orange over $\alpha-\mathrm{Fe}_{2} \mathrm{O}_{3}$-supported $\mathrm{HY}$ catalysts: The effects of catalyst preparation and dealumination. Chem. Eng. J. 2012, 191, 112-122.

27. Boxiong, S.; Yan, Y.A. O.; Hongqing, M.A.; Ting, L.I.U. Ceria modified $\mathrm{MnO}_{x} / \mathrm{TiO}_{2}$-pillared clays catalysts for selective catalytic reduction of $\mathrm{NO}$ with $\mathrm{NH}_{3}$ at low temperature. Chin. J. Catal. 2011, 32, 1803-1811.

28. Kim, H.H.; Kim, J.H.; Ogata, A. Adsorption and oxygen plasma-driven catalysis for total oxidation of VOCs. Int. J. Plasma Environ. Sci. Technol. 2008, 2, 106-112.

29. Trinh, Q.H.; Gandhi, M.S.; Mok, Y.S. Adsorption and plasma-catalytic oxidation of acetone over zeolite-supported silver catalyst. Jpn. J. Appl. Phys. 2015, 54, 01 AG04.

30. Zhu, X.; Gao, X.; Zheng, C.; Wang, Z.; Ni, M.; Tu, X. Plasma-catalytic removal of a low concentration of acetone in humid conditions. RSC Adv. 2014, 4, 37796.

31. Jo, J.-O.; Lee, S.B.; Jang, D.L.; Mok, Y.S. Plasma-catalytic ceramic membrane reactor for volatile organic compound control. IEEE Trans. Plasma Sci. 2013, 41, 3021-3029.

32. Li, W.; Oyama, S.T. Mechanism of ozone decomposition on a manganese oxide catalyst. 2. Steady-state and transient kinetic studies. J. Am. Chem. Soc. 1998, 120, 9047-9052.

33. Ogata, A.; Saito, K.; Kim, H.-H.; Sugasawa, M.; Aritani, H.; Einaga, H. Performance of an ozone decomposition catalyst in hybrid plasma reactors for volatile organic compound removal. Plasma Chem. Plasma Process. 2009, 30, 33-42.

34. Van Durme, J.; Dewulf, J.; Sysmans, W.; Leys, C.; van Langenhove, H. Efficient toluene abatement in indoor air by a plasma catalytic hybrid system. Appl. Catal. B 2007, 74, 161-169.

35. Vandenbroucke, A.M.; Morent, R.; De Geyter, N.; Leys, C. Non-thermal plasmas for non-catalytic and catalytic VOC abatement. J. Hazard. Mater. 2011, 195, 30-54.

36. Lopaev, D.V.; Malykhin, E.M.; Namiot, V.A. UV absorption of vibrationally excited ozone. J. Phys. B 2008, 41, 085104. 
37. Marinov, D.; Guerra, V.; Guaitella, O.; Booth, J.-P.; Rousseau, A. Ozone kinetics in low-pressure discharges: vibrationally excited ozone and molecule formation on surfaces. Plasma Sources Sci. Technol. 2013, 22, 055018.

38. Eliasson, B.; Hirth, M.; Kogelschatz, U. Ozone synthesis from oxygen in dielectric barrier discharges. J. Phys. D 1987, 20, 1421.

39. Yamamoto, T.; Ramanathan, K.; Lawless, P.A.; Ensor, D.S.; Newsome, J.R.; Plaks, N.; Ramsey, G.H. Control of volatile organic compounds by an AC energized ferroelectric pellet reactor and a pulsed corona reactor. IEEE Trans. Ind. Appl. 1992, 28, 528-534.

40. Yagi, S.; Tanaka, M. Mechanism of ozone generation in air-fed ozonisers. J. Phys. D 1979, 12, 1509-1520.

41. Mok, Y.S.; Nam, I.-S. Role of organic chemical additives in pulsed corona discharge process for conversion of NO. J. Chem. Eng. Japan 1998, 31, 391-397.

(C) 2015 by the authors; licensee MDPI, Basel, Switzerland. This article is an open access article distributed under the terms and conditions of the Creative Commons Attribution license (http://creativecommons.org/licenses/by/4.0/). 